\title{
A graphite nodule growth model validated by in situ synchrotron X-ray tomography
}

M K Bjerre' ${ }^{1}$, M A Azeem³,4,5 , N S Tiedje ${ }^{1 *}$, J Thorborg², P D Lee ${ }^{4,5}$, J H Hattel ${ }^{1}$

${ }^{1}$ Department of Mechanical Engineering, Technical University of Denmark, 2800 Kgs. Lyngby, Denmark.

2 MAGMA GmbH, 52072 Aachen, Germany

${ }^{3}$ Department of Engineering, University of Leicester, Leicester LE1 7RH, United Kingdom

${ }^{4}$ Department of Mechanical Engineering, University College London, London, WC1E 7JE, United Kingdom

${ }^{5}$ Research Complex at Harwell, RAL, Didcot, OX11 0FA, United Kingdom

* Corresponding author: nsti@mek.dtu.dk

Keywords: Ductile cast iron, Graphite nodules, Microstructural modelling, Synchrotron X-ray tomography, Solidification.

\begin{abstract}
An accurate prediction of ductile cast iron microstructures is crucial for a science-based optimisation of cast component design. The number density and distribution of graphite nodules critically influence the mechanical performance of a component in service. Although models predicting nodule growth have been researched for many years, recent improvements have been impeded by lack of detailed experimental data on nodule growth kinetics for validation. This data has now been made available through in situ observations of the solidification of ductile cast iron using synchrotron X-ray tomography in combination with a high temperature environmental cell. In the present investigation, a new sphere of influence model for spheroidal graphite growth is proposed. It inherently incorporates the competition for carbon between neighbouring nodules and the depletion of carbon in the matrix. Comparing simulation results to the in situ observations of graphite growth, the sphere of
\end{abstract}


influence model successfully predicts both growth of individual nodules as well as the size distribution of a large nodule population during solidification.

\section{Introduction}

Ductile cast irons (DCI) are known to provide good mechanical performance in terms of fatigue strength and fracture toughness [1] at a low cost, making DCI an important engineering material. The mechanical properties of this family of alloys not only depends on the graphite nodule number density but also the nodule size and shape distributions [2,3]. Graphite nodules form during solidification and the number density of nodules is highly dependent on the thermal conditions of the casting process. In general, the processing conditions play a vital role for the final microstructure and thus the mechanical properties of a DCI component.

To predict the room temperature microstructure of a DCI component from given thermal conditions and melt chemistry, models for nucleation and growth of nodules are crucial. Casting simulations are routinely applied in the component design process for identification of areas where porosity and other microstructural defects are likely to occur. However, such simulations often rely on simplified relations between thermal conditions and predicted microstructure [4].

By tailoring the microstructure it is possible to design lighter structures with improved service life. This requires in-depth knowledge of the basic mechanisms of solidification, allowing identification of suitable melt chemistry and processing routes. Thus, to fully exploit the potential of DCIs, accurate microstructural models are necessary. Through recent emergence of advanced characterisation techniques like synchrotron X-ray imaging and diffraction it is now possible to capture microstructural evolution in real-time.

Synchrotron X-ray sources provide high intensity beams enabling fast imaging of bulk metal objects. In combination with environmental cells, which allow controlled heating of representative sample to temperatures above the melting point of most alloys, synchrotron Xray sources can be used to study the solidification of alloys [5,6,15,7-14] including cast iron 
[16] in real-time. Recently, the first in situ 4D (3D and time) observations from DCI solidification have been presented by the authors [17] allowing a full description of the development of individual nodules and a direct comparison between predictions from microstructural models to time resolved observations of nodule growth.

Based on a thorough analysis of the benefits and limitations of existing models, a new model for graphite nodule growth is suggested. The new model takes into account the effect of competition for carbon between growing graphite nodules. The present investigation then makes full use of the in situ observations to validate the new model by directly comparing model predictions to experimental observations.

\section{In situ observations of DCI solidification}

The synchrotron experiment was performed using the Alice environmental cell [15] at the I12 beam line of the Diamond Light Source, UK. A cylindrical sample $(2 \mathrm{~mm}$ in diameter, $8 \mathrm{~mm}$ in height) of near-eutectic composition was melted and re-solidified while tomograms of the rotating sample were continuously captured. The initial sample composition is provided in table 1. During the experiment, carbon was lost to the surroundings resulting in an estimated final carbon concentration of $3.0 \%$ wt. which was calculated using the total graphite mass after solidification as measured from tomograms obtained after solidification was complete. A thorough description of the experiment and data post-processing has been given in reference [17].

The sample was heated to a maximum temperature of $1167^{\circ} \mathrm{C}$ and then solidified at a cooling rate of $0.03{ }^{\circ} \mathrm{Cs}^{-1}$. A $75 \mathrm{keV}$ monochromatic beam was used and the acquisition was performed using a PCO edge camera with a pixel size of $1.3 \mu \mathrm{m}$. Projections of a $3 \mathrm{~mm}$ tall central region were captured every $0.11 \mathrm{~s}$ and 360 projections were used for reconstruction of each tomogram. Thus, tomograms were acquired consecutively every $40 \mathrm{~s}$, corresponding to $1.2^{\circ} \mathrm{C}$ change in temperature per tomogram. At the maximum temperature any pre-existing graphite had been dissolved indicating that the sample was completely liquid at this point. The time $t=0 \mathrm{~s}$ is assigned to the tomogram recorded at $1138^{\circ} \mathrm{C}$, just before the first graphite appears. Post-processing such as filtering, registration and segmentation based on grey levels was performed in Avizo. 
In this investigation, the nucleation and growth of graphite nodules is evaluated by observing 643 nodules. The nucleation and growth primarily occur over a time interval of $240 \mathrm{~s}$, corresponding to a temperature change of approximately $7^{\circ} \mathrm{C}$. During this interval 6 tomograms were recorded.

Table 1: Initial sample composition, as measured using a spectrometer for all elements except carbon. Carbon content was measured using a LECO CS230. Carbon concentration after solidification was estimated to $3.0 \% \mathrm{wt}$.

\begin{tabular}{|c|c|c|c|c|c|c|c|}
\hline Element & $\mathrm{C}$ & $\mathrm{Si}$ & $\mathrm{Mg}$ & $\mathrm{P}$ & $\mathrm{Cu}$ & $\mathrm{Mn}$ & $\mathrm{S}$ \\
\hline$[\% \mathrm{wt}]$ & 3.6 & 1.9 & 0.075 & 0.017 & 0.012 & 0.099 & 0.001 \\
\hline
\end{tabular}

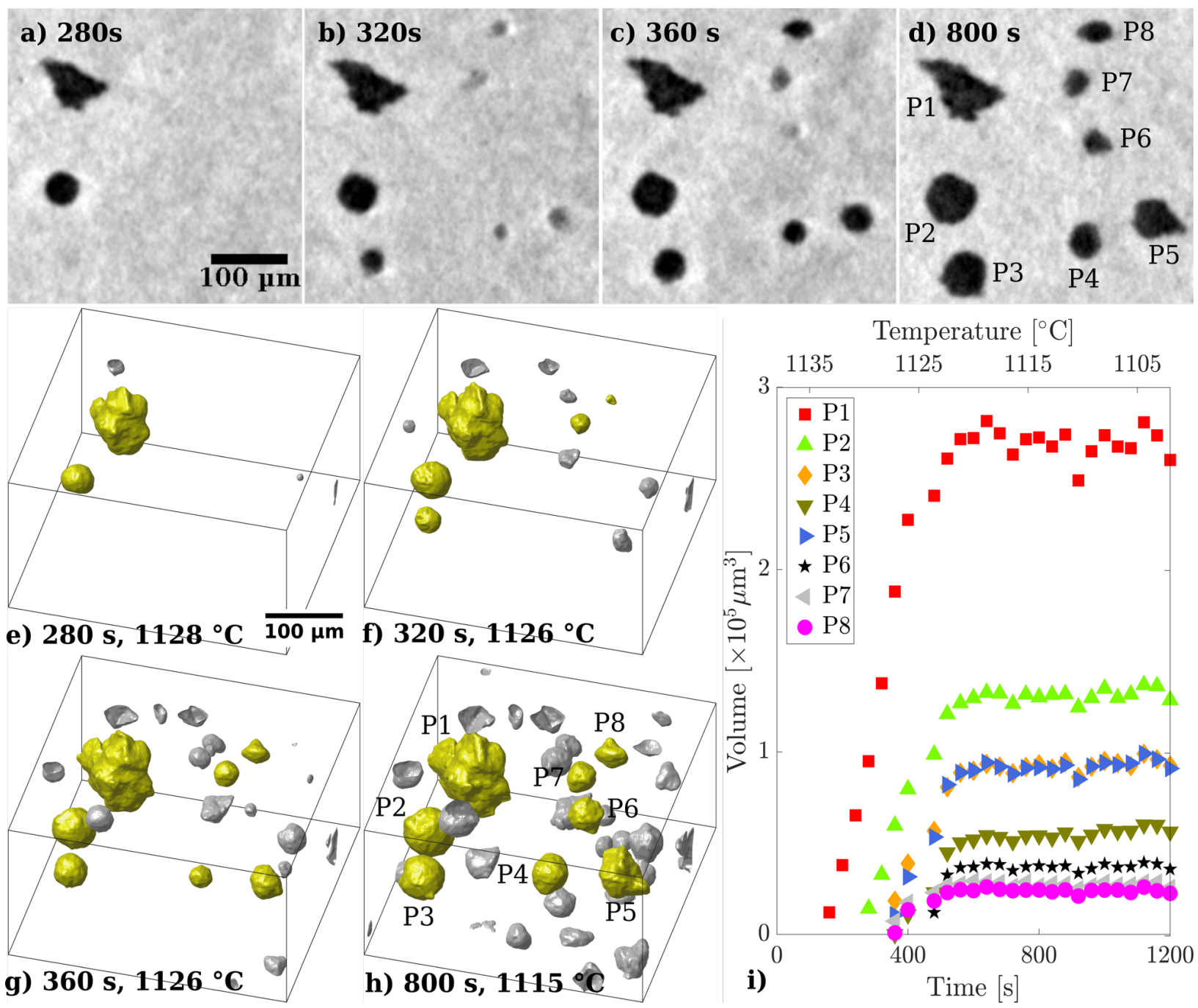


Figure 1. a)-d): In situ tomography time series data showing 2D slices taken from a representative sub volume. The time is given in each frame and the corresponding temperatures are $1130{ }^{\circ} \mathrm{C}, 1128^{\circ} \mathrm{C}, 1127^{\circ} \mathrm{C}$ and $1116^{\circ} \mathrm{C}$. In d) the eight nodules are denoted P1-P8. e)-h): 3D microstructure of the representative sub-volume. Nodules P1-P8 are indicated in $\mathrm{h}$ ) and highlighted in yellow. i) The volume of P1-P8 as a function of time and temperature.

To illustrate the microstructural development, figures 1a-d show 2D sections from a small sub-volume taken from tomograms during solidification (figures 1a-c) and after solidification is complete (figure 1d). The evolving dark phases are individual graphite nodules and the surrounding bright regions comprised of austenite ( $($-Fe) and liquid, which remain indistinguishable due to similar X-ray attenuation characteristics. Due to the loss of carbon during the experiment, a significant amount of austenite is expected to form before the first graphite. The difference in attenuation between graphite and the surroundings is exploited for segmentation of individual graphite nodules, enabling their growth during the course of solidification to be tracked (see labelled nodules in figures $1 \mathrm{~d}$ and $1 \mathrm{~h}$ ). Tracking individual graphite nodules through consecutive segmented tomographic volumes allows a description of the development of nodule volume as a function of time and temperature. The development of the 3D microstructure in the small sub-volume is shown in figures 1e-h. P1-P8 are highlighted in figure $1 \mathrm{~d}$ and $\mathrm{h}$ and their volumes are shown as a function of time and temperature in figure 1i. An error occurred while recording the tomogram at $440 \mathrm{~s}$ resulting in a gap in the data. Notice that the graphite nodules motion is negligible during the course of solidification, indicating that nodules remain fixed by austenite during the course of solidification [17].

Figures 1a-d clearly show the formation order of the graphite nodules. Traditionally [18-21], colour etchings and mappings by microprobe have been used to study the segregation of silicon during solidification and thus to derive information about the sequence in which microstructure evolves. Mapping by energy dispersive spectroscopy (EDS) is a less involved process and the result provides a good overview of silicon segregation and the location of the last-to-solidify zones [17]. The area around P1-P8 was investigated in the final microstructure using light optical microscopy (LOM) and EDS, figures 2a-c. From the Si distribution in figure 
$2 \mathrm{~b}$ it is evident that the large nodule P1 is confined to a Si rich region while relatively smaller nodules, such as P6, are confined to zones of lower Si concentration. This indicates that P1 nucleated early while P6 formed towards the end of solidification, in agreement with the in situ observations in figures $1 \mathrm{a}-\mathrm{d}$. This conclusion supports the finding that silicon redistribution during solid state transformation is limited [22]. Mg-containing particles, likely oxides, are indicated in figure 2c. The EDS maps of silicon and magnesium (figures $2 \mathrm{~b}$ and 2c), suggest that the Mg-containing particles were rejected to the last-to-solidify melt but did not act as active sites for graphite nucleation.

The following section discusses growth of graphite nodules in the light of the in situ observations and existing models for nodule growth.
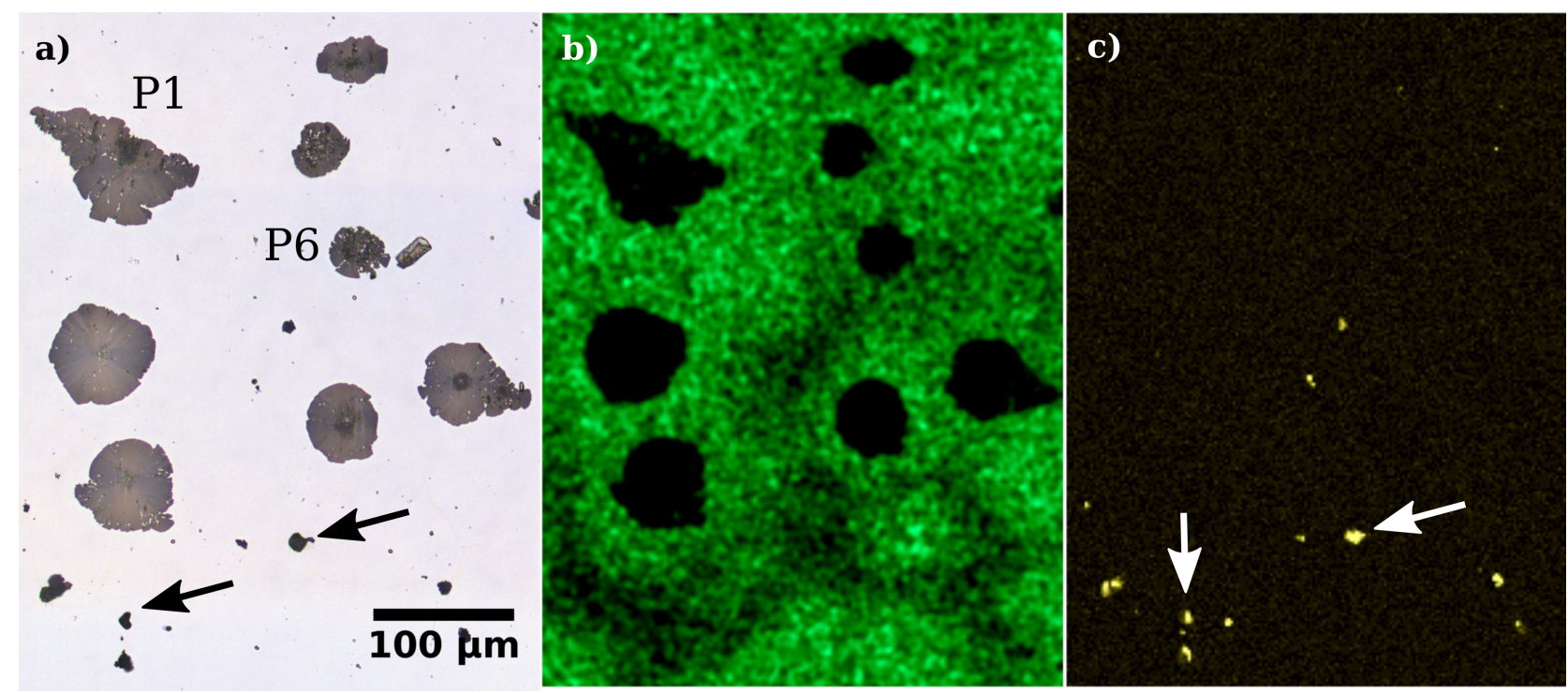

Figure 2. a): Microstructure around nodules P1-P8 observed at room temperature by Light Optical Microscopy. Nodules P1 and P6 are indicated. Energy Dispersive Spectroscopy maps of silicon and magnesium distribution at room temperature are shown in b) and c) respectively. Two Mg-containing particles are pointed out in a) and c). 


\section{The graphite nodule growth stages in a Fe-C alloy}

The growth of graphite nodules during solidification and solid state cooling in a DCI alloy can be divided into four stages:

i Free growth: Upon nucleation, the graphite nodule grows in direct contact with the melt.

This type of growth is assumed to be governed by the interface kinetics of incorporating carbon atoms into the nodule [23].

ii Encapsulated growth: After the nodule is encapsulated in austenite, the growth of the nodule is governed by the diffusion of carbon from the carbon-rich melt towards the nodule through the encapsulating austenite shell.

iii Low supersaturation growth: After solidification, nodule growth is driven by the decreasing solubility of carbon in austenite as the alloy is cooling. The austenitic matrix has a low carbon supersaturation resulting in slow nodule growth.

iv Transformation-driven growth: The transformation of the matrix from austenite to ferrite is associated with a large decrease in carbon solubility. A part of the rejected carbon further contributes to growth of graphite nodules in solid state.
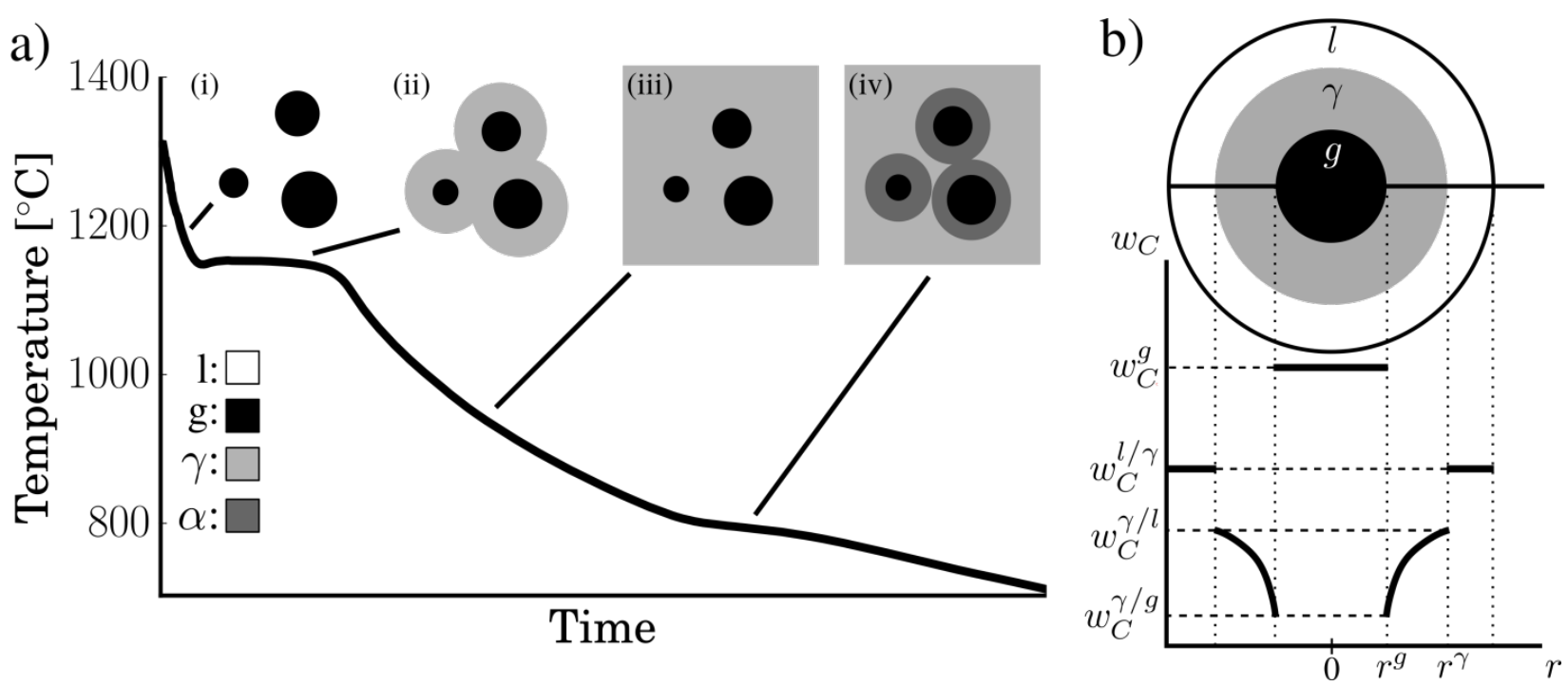

Figure 3. a): Schematic illustration of the relation between the growth stages (i)-(iv) and the casting temperature. The four different phases, liquid (l), graphite $(\mathrm{g})$, austenite $(\gamma)$ and ferrite $(\alpha)$, are indicated by different grey levels. b): Schematic illustration of the distribution of carbon in the uni-nodular model.

The different growth stages are schematically depicted as a function of temperature in figure 3a. It is possible that during very initial stages of growth, the nodules nucleate and translate to 
a different location. However, it is not possible to confirm such movements due to imaging resolution limit of the current investigation. In the current investigation, from the moment the nodules become visible and until the solidification finishes, they remain fixed in space. At the same time, new nodules nucleate over a significant time and temperature interval showing that the present in situ experiment captures the second and third growth stages as well as the transition between the two stages. For the encapsulated growth stage, the uni-nodular (UN) approach has become the reference model. This model considers a closed unit volume where a single nodule of radius, $r^{g}$, is located at the centre of the volume. During the encapsulated growth stage, the nodule is assumed to be surrounded by a perfectly spherical austenite shell of outer radius, $r^{\gamma}$, as illustrated by figure $3 \mathrm{~b}$. Within the UN model, the encapsulated nodules are disconnected from each other and the inter-nodular space is assumed to be occupied by liquid. The presence of liquid is assumed to sustain a continuous flow of carbon towards the encapsulated nodule during solidification. This is reflected by assuming a quasi-stationary carbon concentration profile, $w_{c}^{\gamma}(r)$, of the austenite shell

$w_{c}^{\gamma}(r)=w_{C}^{\gamma / g}-\frac{r^{\gamma} r^{g}}{r^{\gamma}-r^{g}}\left(w_{C}^{\gamma / l}-w_{C}^{\gamma / g}\right)\left(\frac{1}{r^{g}}-\frac{1}{r}\right)$

where $w_{C}^{\gamma / g}$ and $w_{C}^{\gamma / l}$ are the carbon concentrations of austenite in equilibrium with graphite and liquid respectively. The growth rate equations resulting from these assumptions were first presented by Wetterfall et al. [24] and the analysis was further expanded by Lesoult et al. [25]. In this investigation, the latter is referred to when considering the predicted growth rate within the uni-nodular framework. It is given as

$\dot{r}_{O}^{g}=\frac{\mathrm{d} r^{g}}{\mathrm{~d} t}=\frac{\rho^{\gamma}}{\rho^{g}} D_{C}^{\gamma} \frac{r^{\gamma}}{r^{g}\left(r^{\gamma}-r^{g}\right)} \frac{w_{C}^{\gamma / l}-w_{C}^{\gamma / g}}{1-w_{C}^{\gamma / g}}$

where $D_{C}^{\gamma}$ is the diffusion coefficient of carbon in austenite and $\rho^{\gamma}$ and $\rho^{g}$ are the densities of austenite and graphite, respectively. The assumed distribution of carbon within the unit volume is schematically illustrated in figure $3 \mathrm{~b}$. The above equation can also be written in a more compact form 
$\dot{r}_{O}^{g}=\mathrm{H}(T) \cdot \mathrm{F}\left(r^{g}, r^{\gamma}\right) \cdot \Delta w_{C}(T)$

$H(T)=\frac{\rho^{\gamma}}{\rho^{g}} \frac{D_{C}^{\gamma}}{1-w_{C}^{\gamma / g}} ; \quad \mathrm{F}\left(r^{g}, r^{\gamma}\right)=\frac{r^{\gamma}}{r^{g}\left(r^{\gamma}-r^{g}\right)} ; \quad \Delta w_{C}(T)=w_{C}^{\gamma / l}-w_{C}^{\gamma / g}$

where $\Delta w_{C}$ corresponds to the carbon concentration difference which drives the flow of carbon towards the nodule. An additional equation describes the growth of the austenite shell

$\frac{\mathrm{d} r^{\gamma}}{\mathrm{d} t}=\frac{D_{C}^{\gamma} \cdot r^{\gamma}}{r^{g}\left(r^{\gamma}-r^{g}\right)} \frac{w_{C}^{\gamma / l}-w_{C}^{\gamma / g}}{w_{C}^{l / \gamma}-w_{C}^{\gamma / l}}\left(1+\frac{\rho^{\gamma}-\rho^{g}}{\rho^{g}} \cdot \frac{w_{C}^{\gamma / l}-w_{C}^{\gamma / g}}{1-w_{C}^{\gamma / g}}\right)$

where $w_{C}^{l / \gamma}$ is the carbon concentration of the melt in equilibrium with austenite. Although the assumed arrangement of austenite, liquid and graphite in the UN model permits a mathematically simple description of nodule growth it also has intrinsic limitations. During solidification, austenite dendrites encapsulate multiple nodules which results in nodule interaction through overlapping diffusion fields and growth competition. Thus, the basic assumption of the uni-nodular approach, that a nodule and its surrounding austenite shell is effectively isolated from its neighbours, is compromised. As a direct consequence the transition between growth stages (ii) and (iii) is not described in the UN model.

Recently, the UN model was extended $[17,26]$ to include the growth of graphite after solidification is complete corresponding to the third growth stage listed above. The extension results in a relatively sharp transition from encapsulated growth to low supersaturation growth during solid state cooling when solidification of the unit cell is complete. Although the model extension performed much better than the UN model alone the extension is not applicable for casting simulations. The reason is the assumed prior knowledge of the extent of the unit cell for each nodule or, at least, for a family of nodules. Further, a comparison to experimental observations showed that further improvements are needed including a better description of the gradual transition from encapsulated growth to low supersaturation growth during solid state cooling.

An early attempt to model the transition between encapsulated growth and low supersaturation growth during solid state cooling was made by Boeri [27]. That study was 
inspired by an investigation from Su et al. [28] to modify the growth rate equation, equation (2), such that the nodule growth rate decreases with increasing solid fraction according to [29]

$\dot{r}_{J}^{g}=J \cdot \dot{r}_{O}^{g} ; \quad J=0.9 \cdot\left(1-f_{S}\right)^{2 / 3}$

With this expression, the growth rate, $\dot{r}_{J}^{g}$, is assumed equal to zero after solidification is complete, which is a reasonable simplification given the very low expected growth rates at this stage. $J$ and especially the numeric pre-factor 0.9 appear to be the result of somewhat arbitrary choices which are not sufficiently supported by experimental evidence. Comparing the results of casting simulations to experimental observations has so far been the main tool applied to validate the different microstructural models [29-33] as direct observations of graphite growth have been unavailable. This approach has the disadvantage that it tests the thermal solver and choice of nucleation model as well as the microstructural growth model. As a result the comparison of experiment and simulation does not provide a sufficiently detailed basis for validating the microstructural model itself.

From the analysis of the in situ observations previously presented it was clear that the description presented by Lesoult et al. [25] yielded predictions of growth rates, which, during early stages of solidification agree well with the experimental observations [17]. However, the experimental data showed a significant and continuous overall drop in graphite nodule growth rates towards the end of solidification. This observation was attributed to the partial depletion of carbon from the austenite matrix even at relatively low solid fractions. This does not agree with the assumptions of the UN model which for the same reason predicts growth rates much higher than what is experimentally observed at the late stages of solidification. The suggested growth model by Boeri [27] predicts a gradual decrease in nodule growth rates. Its exact formulation is, however, questionable as it assumes decreasing growth rates from the beginning of solidification, which is a divergence from the experimental observations. Instead, a modification should, according to the presented experiment, only take effect at late stages of solidification. 
By comparing growth rates of neighbouring nodules and taking into account the arrangement of graphite, austenite and liquid, Bjerre et al. [34] found that proximity of a nodule to the lastto-solidify regions contribute to high growth rates even during late stages of solidification. Nodules situated among several neighbours exhibited sluggish growth and the overall growth plateaued relatively early. This illustrates the effect of carbon depletion in the austenite on the competitive growth between neighbouring nodules. The effect causes large individual variations in nodule growth rates.

Thus, it seems necessary to consider the effect of overlapping diffusion fields when revisiting graphite nodule growth models but also that this effect only plays a role at late stages of solidification. Impingement of diffusion fields has previously been included in similar models for porosity growth in Al-Si castings [35,36]. Although the need for a modification or revision of the UN model is clear, it is remarkable that the predicted growth rate corresponds well to the experimental observations, especially considering the amount of austenite present before the first graphite formed. Thus, even though the actual arrangement of austenite and graphite does not correspond with the idealised UN model, the carbon concentration field assumed in the model seems to provide a reasonably good approximation.

\section{Sphere of influence model for nodule growth}

It is clear that the UN model described above provides an incomplete picture of the graphite nodule growth at late stages of solidification. In the case where multiple nodules are embedded in an austenite grain, which itself is surrounded by carbon-rich liquid, it is not immediately clear how the carbon is distributed around each nodule.

The UN model assumes a spherically symmetric austenite shell in which the carbon concentration depends linearly on $r^{-1}$ as illustrated in figure $3 \mathrm{~b}$. Above it was made clear that this is a reasonable approximation for initial stages of growth. However, this arrangement of austenite, graphite and liquid, assumed in the UN model is a biased representation of the actual observed microstructure during the course of solidification. Thus, rather than assuming a perfect austenite shell around each nodule, we introduce a sphere of influence around each 
nodule. Within this sphere, the carbon level is below the concentration predicted by austenite-liquid equilibrium due to nodule growth.

Figure 4 schematically illustrates the solidification of DCI where the spheres of influence are depicted. Initially, there is no interaction between the spheres of influence, as shown in figure 4a. As the solidification progresses, the spheres of influence expand and impinge as shown schematically for two time steps in figure $4 \mathrm{~b}$ and c respectively. As soon as the spheres of influence impinge, the carbon concentration around a nodule cannot be described by equation (1) and the flow of carbon towards the nodules will be reduced. This will lead to a reduction in growth rate similar to the behaviour observed by Azeem et al. [17].

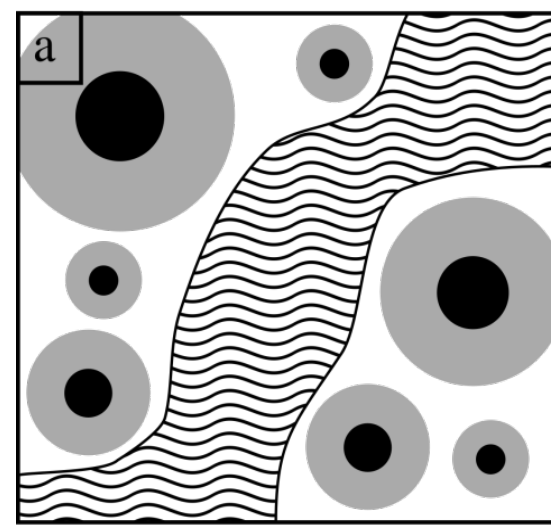

$\square$ : Austenite
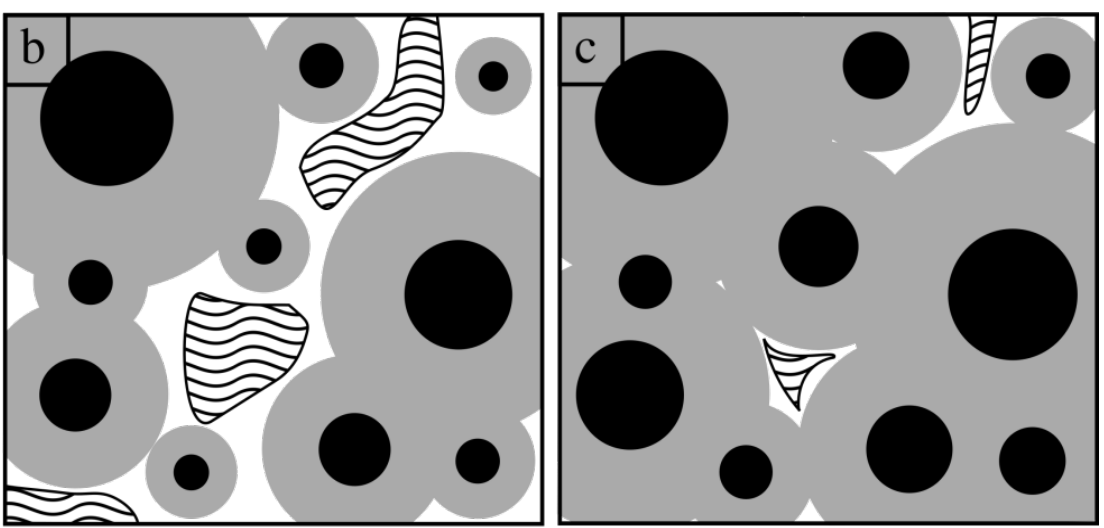

ㅋ: Liquid

: Sphere of influence

Figure 4. a-c: Schematic illustration of microstructural phases in a DCI solidification process. The sphere of influence for each nodule is illustrated by the grey shading.

The different nodules in figure 4 experience varying degrees of overlap between their spheres of influence which lead to variations in growth rate among nodules which are otherwise comparable [34]. The purpose of modifying the UN model is however not to describe in detail the individual variations in growth rates but rather to capture the overall growth behaviour. In order to achieve this, the approach by Boeri [27] is adopted such that equation (2) is multiplied by a factor $M$. From the previous discussion $M$ needs to fulfil two requirements: a) only impose a reduction in growth rate above a certain solid fraction expressing the impingement of spheres of influence and $b$ ) The growth rate must be equal to zero at a solid fraction equal to 1 . The simplest choice is a linear relation: 
$\dot{r}_{M}^{g}=M \cdot \dot{r}_{O}^{g} ; \quad M=\left\{\begin{array}{c}1 \text { if } f_{s}<f_{s}^{*} \\ \frac{f_{s}-1}{f_{s}^{*}-1} \text { if } f_{s} \geq f_{s}^{*}\end{array}\right.$

With the above equation the growth rate decreases with increasing solid fraction for $f_{s} \geq f_{S}^{*}$ such that the growth rate is 0 at $f_{s}=1$. Equation 7 will be referred to as the Sphere of Influence (SoI) model in contrast to the UN model expressed by equation (2). The modifying factor $M$ can be included in a new expression for $\Delta w_{C}$ in equation (3) such that

$\Delta \widetilde{w}_{C}\left(T, f_{s}\right)=M\left(f_{s}\right) \cdot \Delta w_{C}(T)$

which illustrates that this type of modification is equivalent to imposing a decreasing carbon supersaturation which leads to a reduction in the nodule growth rate. Equation (7) contains a single parameter which needs to be determined, namely $f_{s}^{*}$, which is effectively the solid fraction at which the reduction in carbon supersaturation is imposed.

The UN model predicts a ratio $r^{\gamma} / r^{g}$ which is approximately equal to 2.4 , a result which has been experimentally verified [24,37]. Considering the previous discussion $r^{\gamma}$ is replaced by the sphere of influence radius $r_{S o I}$ which is assumed equal to $2.4 \cdot r^{g}$. Thus $F\left(r^{g}, r^{\gamma}\right)$ in (3) becomes

$F\left(r^{g}, r_{\mathrm{SoI}}\right)=\frac{r_{\mathrm{SoI}}}{r^{g}\left(r_{\mathrm{SoI}}-r^{g}\right)}=\frac{2.4}{1.4 r^{g}}$

This modification only changes model predictions marginally but the austenite volume fraction can now be calculated by assuming equilibrium between austenite and liquid, which affects the calculation of the solid fraction in a casting simulation.

Given that the purpose of the model is to capture the average nodule behaviour it seems appropriate to associate $f_{S}^{*}$ to the point in time where the average nodule sphere of influence radius exceeds half of the average spacing between nodules. Following the above discussion we now assume that all nodules have a sphere of influence with a radius of $r_{\text {SoI }}=2.4 r_{e q}^{g}, r_{e q}^{g}$ being the equivalent radius of each experimentally observed nodule calculated by assuming 
that each nodule is perfectly spherical. From this, the radius of the average sphere of influence can be calculated as a function of time in the experimental data. The average spacing between randomly distributed nodules, $\Delta l$, can be calculated from [38]:

$\Delta l=\frac{0.554}{\sqrt[3]{N}}$

where $N$ is the number density of nodules. The average $r_{\text {SoI }}$ and $\Delta l / 2$ from the experimental data is presented in figure 5 as a function of estimated solid fraction. The extent of the average sphere of influence exceeds half of the average spacing between nodules at a solid fraction of 0.62 . According to the above analysis, it is from this instance that the growth of nodules on average starts to be affected by the decreasing availability of carbon and thus $f_{S}^{*}=0.62$ in the experiment.

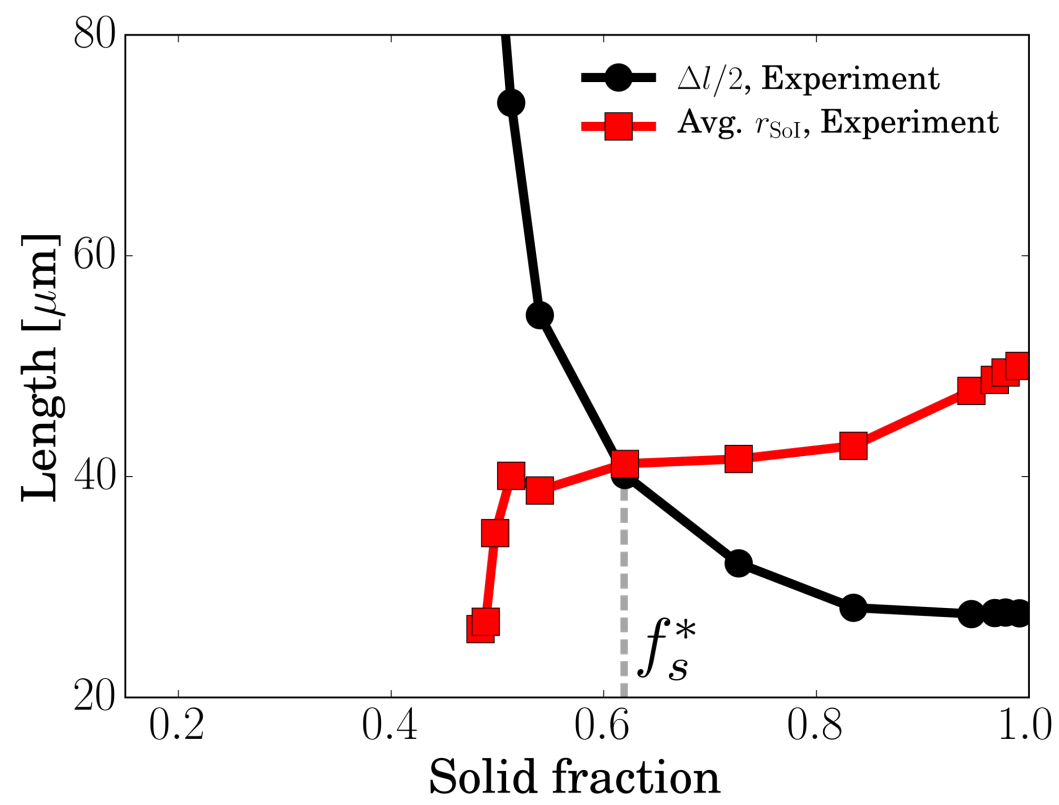

Figure 5. Half average spacing between nodules $\Delta l / 2$ and average radius of the spheres of influence $r_{\text {SoI }}$ obtained from experimental data plotted as a function of solid fraction. Curves intersect at a solid fraction of 0.62 which defines $f_{s}^{*}$ for the experiment.

The solid fraction as a function of time was not measured directly from the in situ observations because of the very low X-ray attenuation difference between the liquid metal and the solid austenite. Instead, the solid fraction was estimated using the observed graphite 
volume and the calculated nominal carbon content. By additionally assuming that austenite and liquid remain in equilibrium throughout solidification the solid fraction can be estimated as detailed elsewhere[17,26]. Since the average SoI as well as the average distance between nodules are highly dependent on the actual density of nodules as well as the nodule size distribution, $f_{s}^{*}$ cannot be given a priori but needs to be measured experimentally or simulated.

To illustrate how $f_{s}^{*}$ varies under different process parameters, DCI solidification was simulated at a carbon concentration of $w_{C}=3.0 \% \mathrm{wt}$. corresponding to the composition of the in situ experiment as well as for $w_{C}=3.4 \% \mathrm{wt}$. and $3.7 \% \mathrm{wt}$. In all cases the remaining conditions mimic those of the in situ experiment and thus a constant cooling rate of $0.03{ }^{\circ} \mathrm{C} \mathrm{s}^{-1}$ is imposed and a silicon concentration of $w_{S i}=1.9 \% \mathrm{wt}$. is used. A detailed description of the algorithm employed to simulate DCI solidification can be found in the supplementary note 1 . As a part of the supplementary, two Python scripts for simulating DCI solidification and plotting the results are provided. The solidification model is based on the work of Lacaze et al. [30] and Pedersen et al. [32,39] who took impingement into account only when calculating the total graphite volume. An Oldfield-type of nucleation law is used with parameters obtained from the in situ experiment [17]. Thus, in all simulated cases the nucleation starts at an undercooling of $138{ }^{\circ} \mathrm{C}$ with respect to the graphite liquidus and the final nodule count is constant across simulations. $N_{i}$ is the number of nodules which nucleated during time step $i$. The radius of all these nodules develop according to the nodule growth equation, equation (7), such that after time step $j$ the radius of the $N_{i}$ nodules, $r_{i, j}^{g}$, with implicit time integration is calculated as

$$
\begin{aligned}
& r_{i, j}^{g}=\frac{1}{2}\left(r_{i, j-1}^{g}+\sqrt{\left(r_{i, j-1}^{g}\right)^{2}+4 a \delta t}\right) \\
& a=\frac{\rho^{\gamma}}{\rho^{g}} D_{C}^{\gamma} \frac{2.4}{1.4} \frac{w^{\gamma / l}-w^{\gamma / g}}{1-w^{\gamma / g}} \cdot M
\end{aligned}
$$

where $\delta t=0.1 \mathrm{~s}$ is the length of each time step and $r_{i, j-1}^{g}$ is the radius of each of the $N_{i}$ nodules after the $j-1$ 'th time step. The densities $\rho^{\gamma}=7200 \mathrm{~kg} \mathrm{~m}^{-3}, \rho^{l}=6900 \mathrm{~kg} \mathrm{~m}^{-3}$ and $\rho^{g}=2200 \mathrm{~kg} \mathrm{~m}^{-3}$ are used and following Pedersen et al. [32], the diffusion coefficient of carbon was set to vary with temperature according to $D_{C}^{\gamma}=7.7 \cdot 10^{-6} \cdot \exp \left(-\frac{15260 K}{T}\right) \mathrm{ms}^{-2}$ 
where the temperature $T$ is expressed in Kelvin. Austenite and liquid volume fractions are calculated by assuming conservation of total mass and carbon mass and using a linear approximation of the Fe-C phase diagram [30].

Figure 6 presents the half average nodule spacing $\Delta l / 2$ and average $r_{\text {SoI }}$ from simulations with three different carbon compositions. At near-eutectic composition $\left(w_{C}=3.7 \% \mathrm{wt}, w_{S i}=1.9\right.$ $\% \mathrm{wt}$ ) only a small amount of austenite has formed before graphite nucleation is initiated. Initially, the average $r_{\text {SoI }}$ is small and the $\Delta l / 2$ is large. As the solidification progresses they become equal momentarily following which the $r_{\text {SoI }}$ increases while the $\Delta l / 2$ decreases. During solidification, a small decrease in the average $r_{\text {SoI }}$ can be observed in each simulation due to the rapid nucleation of new nodules. As the nucleation ceases, the average $r_{\text {SoI }}$ increases again. The fraction solid, $f_{s}^{*}$, at which the average $r_{\text {SoI }}$ is equal to $\Delta l / 2$ decreases as the carbon concentration increases across the three simulations. Similarly, $f_{s}^{*}$ is influenced by melt inoculation state and cooling conditions.

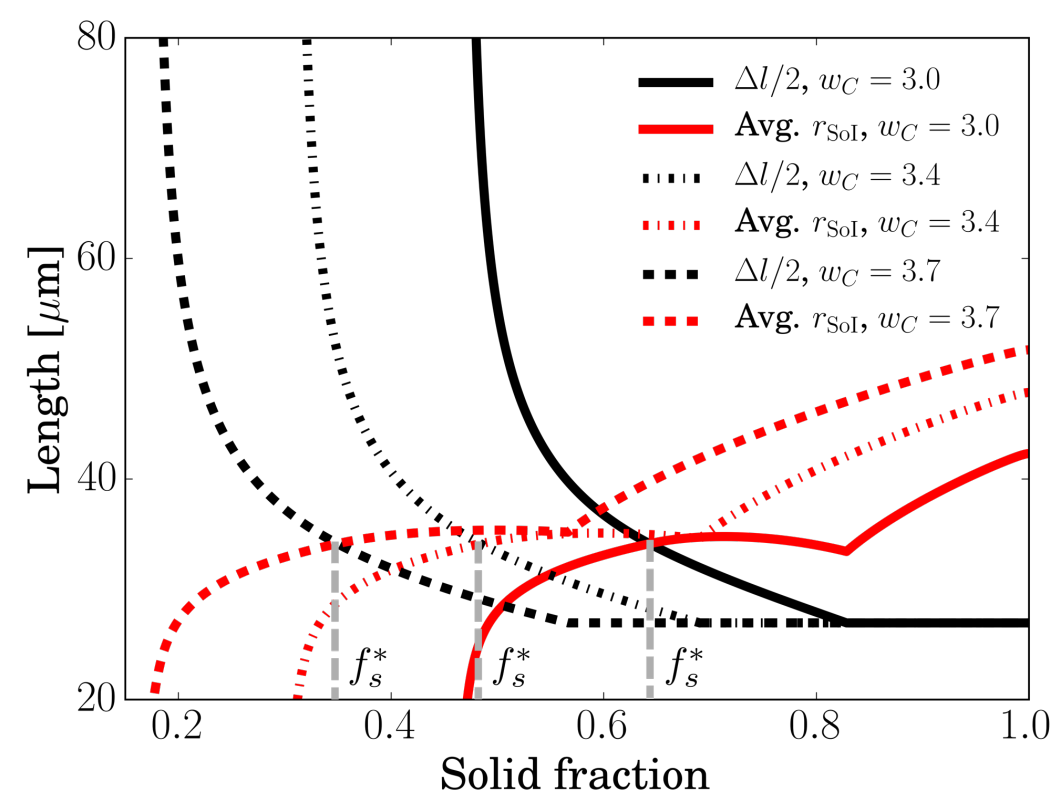

Figure 6. Half average nodule spacing $\Delta l / 2$ and average $r_{\text {SoI }}$ obtained from DCI solidification simulations with nominal carbon concentrations, $w_{C}$, of $3.0 \% \mathrm{wt}$., $3.4 \% \mathrm{wt}$. and $3.7 \% \mathrm{wt}$. Thermal conditions as well as melt inoculation state mimic those of the in situ experiment. 


\section{Model validation}

The validation of the model is divided into two parts: The first comparison focuses on nodule growth in terms of the relation between nodule volume and time and between nodule volume and nodule growth rate. Secondly, the SoI model is used to predict the development of the nodule size distribution during solidification. In all cases the results are compared with experimental observations.

\subsection{Nodule growth}

The growth of individual nodules is simulated under conditions which correspond to those of the in situ experiment as described in the previous section and supplementary note 1 . Nodule growth is initiated at the estimated time of nucleation obtained by extrapolation from the first observation of a nodule down to a nodule radius of $1 \mu \mathrm{m}$. This method of estimating nucleation time and temperature has previously been employed for graphite nodules in DCI and porosities in $\mathrm{Al}-\mathrm{Cu}$ alloys $[17,40]$.

In figure 7 the volume of four regular nodules, N1 to N4, is presented as a function of time from experimental observations as well as simulated predictions. The experimental data for N1-N4 all display an initial growth stage followed by a transition to a regime of little or no growth reflecting first the encapsulated growth followed by a transition to low supersaturation growth during solid state cooling. The growth rate in the later stage is too small to be observable within the considered time range. For each of the four nodules a simulation using the SoI growth model is presented. For the nodule N1 the growth was also simulated using the UN model, equation (2), and the effect of the model modification can be clearly observed: Initially, the two models accurately predict the fast growth rates with both UN and SoI model curves overlapping. Later, the UN model predicts an accelerated growth rate while the prediction from the SoI model shows a gradual growth rate reduction. Comparing the observed and predicted relation between nodule volumes and time for the four regular nodules, it is clear that the SoI model prediction is close to the observed behaviour, including the accurate prediction of gradual transition between encapsulated growth and low supersaturation growth during solid state cooling. The final volume of N2 and $\mathrm{N} 3$ is overestimated while it is underestimated for $\mathrm{N} 1$ and well predicted for N4. This is not a 
surprise given the individual differences in growth conditions which result in growth rate variations between otherwise similar nodules as discussed by Bjerre et al. [34].

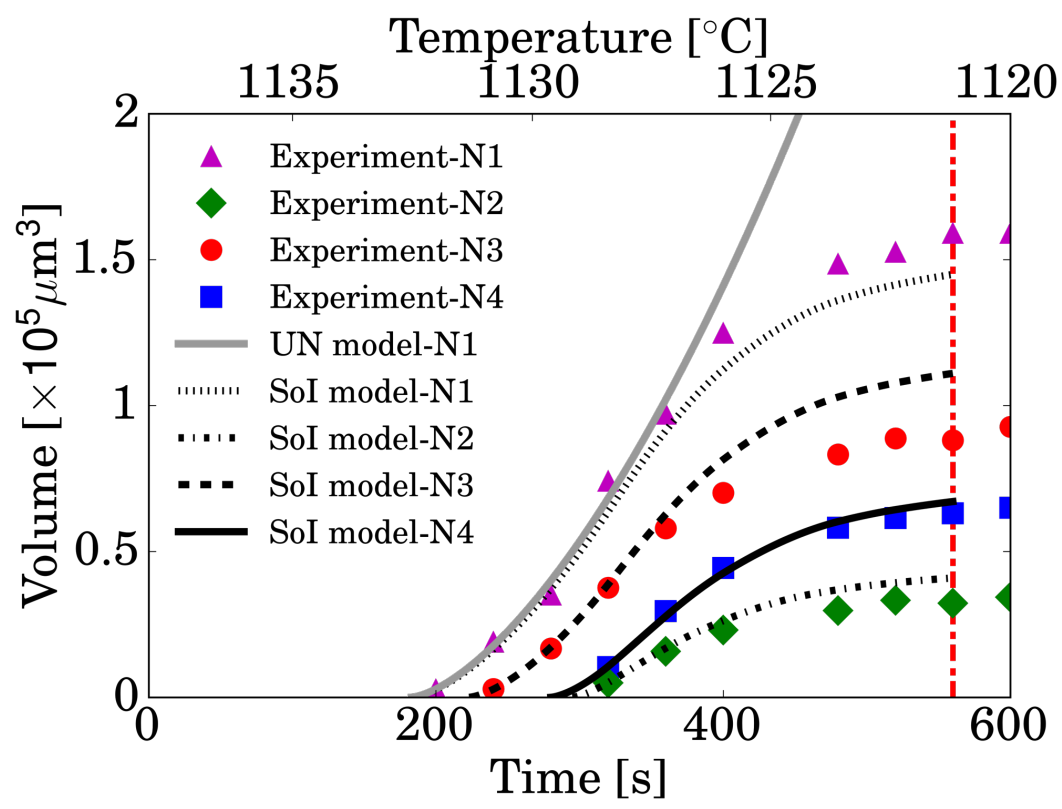

Figure 7. Simulated and observed volume of 4 selected nodules, N1 to N4, as a function of time. The vertical red line indicates the end of solidification.

To further test if the model successfully describes the general variations in growth rate through time and across different nodule volumes, the predicted relation between nodule volume and growth rate at specific instances of time is now compared to the experimental observations. For an experimentally observed nodule with the volume $V_{s}$ at time $t_{s}$ and $V_{s+1}$ at the subsequent time instance $t_{s+1}=t_{s}+\Delta t$ the growth rate is calculated as $\left(V_{s+1}-V_{s}\right) / \Delta t, \Delta t$ being the time between tomographic scans. Graphite nodules were sorted by their volumes, $V_{S}$, and grouped in bins of 10 nodules. The average $V_{S}$ and growth rate is then calculated within each bin. This is repeated for three different $t_{s}$. Since nucleation is continuous the number of nodules and thus the number of data points at each $t_{s}$ increases with time. The results are shown in figure 8 for regular nodules (sphericity $\Psi=\pi^{1 / 3}(6 V)^{2 / 3} A^{-1}>0.75$ ), $V$ and $A$ being the volume and surface area of the nodule. Clearly, a gradual reduction in the growth rate for all nodule volumes is observed as the solidification progresses, reflecting the transition from encapsulated growth to low supersaturation growth during solid state cooling. 
Each experimental data set represents the growth rate observed as a function of nodule volume between two time instances. Each of these time intervals is associated with an average temperature and solid fraction that are then used to calculate the corresponding relations predicted by the SoI model. The model predictions are represented as full lines in figure 8 for each $t_{s}$ and the associated solid fraction, $f_{s}$, used in the expression for $M$ in equation (7), is given in the figure legend. Note that for $t_{s}=280 \mathrm{~s}$ the solid fraction is below $f_{s}^{*}$ which means that the SoI model at this stage is equivalent to the UN model. At $t_{s}=280 \mathrm{~s}$ the comparison to a limited number of data points shows that overall the growth rates and the observed trends are very well predicted by the model although there is a minor overestimation of the growth rates of small nodules. At later stages, where the SoI model modification takes effect, the agreement between the model predictions and the experimental observations is good over a large range of nodule volumes. The ability to predict the reduction in growth rate, as observed from $t_{s}=280 \mathrm{~s}$ to $t_{s}=360 \mathrm{~s}$ is only possible via the SoI model. This expresses a significant improvement as the curve for $t_{s}=280 \mathrm{~s}$, corresponding to the UN model, dramatically overestimates the growth rates observed at late stages in the solidification.

The current investigation only considers growth of regular nodules to ensure a relevant experimental basis for comparison to simulated results. However, irregular nodules have been observed to grow faster than regular nodules [17] and the presence of irregular graphite nodules reduces the yield and tensile strengths in DCI components [3]. Murcia et al. [41] approached this problem by assuming a partial encapsulation of nodules by austenite during solidification leading to a prediction of average nodularity. It might be necessary to include extreme growth behaviours in future models for microstructure development in order to provide better prediction of structures which might lead to component failure. 


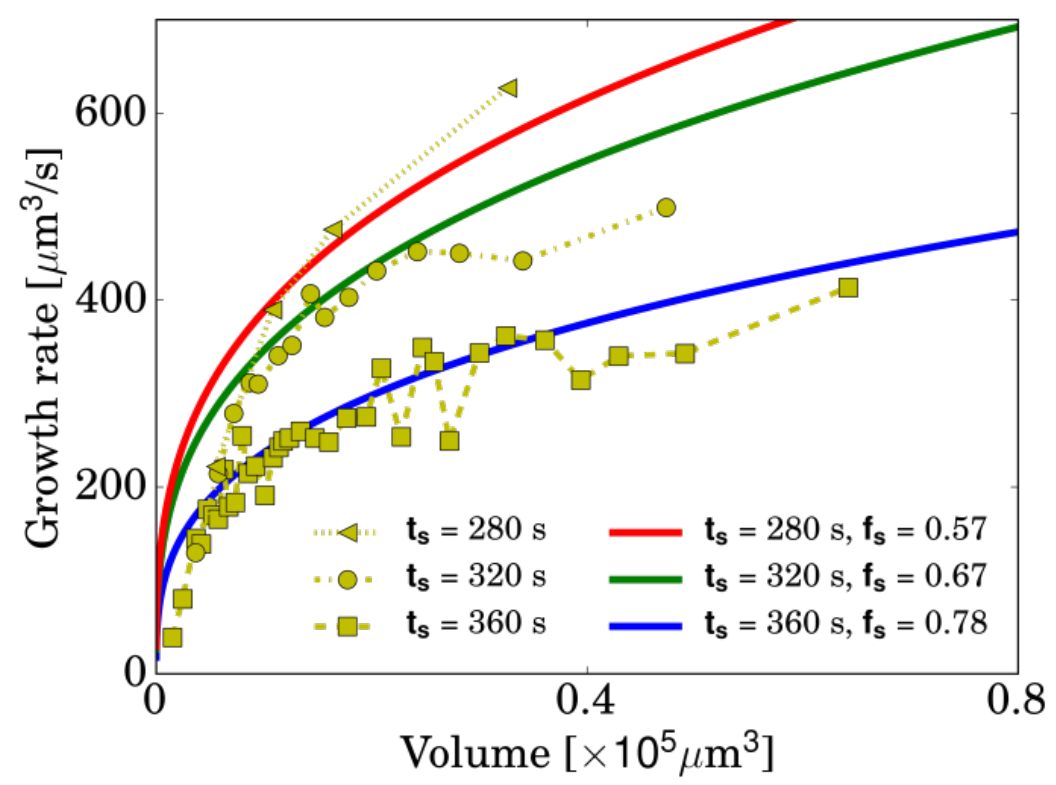

Figure 8. Relation between nodule volume and growth rate as observed from experiment (symbols) and predicted by the SoI model (solid lines). The curve predicted for $t_{s}=280 \mathrm{~s}$ corresponds to the UN model since $f_{s}=0.57<f_{s}^{*}$.

\subsection{The development of a population of graphite nodules}

It is clear that the SoI growth model accurately predicts the average nodule growth behaviour. In this section, we evaluate the feasibility of using the model to predict the development of the nodule size distribution and thus evaluate if the shape of the distribution is dominated by average nodule growth behaviour or not. Most simulations of the solidification of DCI components [29-33] assume that this is the case although it has not been sufficiently investigated.

The experimentally observed nodule density is presented as a function of time in figure 9 . As specified before, the nucleation instance of each nodule is estimated using extrapolation down to a radius of $1 \mu \mathrm{m}$ from the nodule volume from when it was first observed during in situ tomography experiment. It is clear that nucleation is continuous and that the nucleation rate increases with time and undercooling. Graphite nodule nucleation starts at an undercooling of approximately $150{ }^{\circ} \mathrm{C}$ with respect to the graphite liquidus which indicates a low initial nucleation potency of the melt. The rapid increase of the nucleation rate after nucleation indicates that the onset of the eutectic solidification is a self-accelerating process. As reported 
by Muhmond and Fredriksson [42], the cast iron solidification progresses via segregation of elements ahead of the solidifying front, thus leading to precipitation of oxide and sulphide particles which act as graphite nucleation sites. In figure 2, Mg-containing particles, likely oxides, are found in the last-to-solidify melt supporting this hypothesis. Despite this, nucleation ends before solidification is complete. It thus seems that the large Mg-bearing particles in the last-to-solidify melt are unfavourable nucleation sites for graphite or that the local thermal and chemical conditions did not allow graphite to form in the last pockets of liquid. The nucleation data is critical for estimating nodule size as presented in following sections.

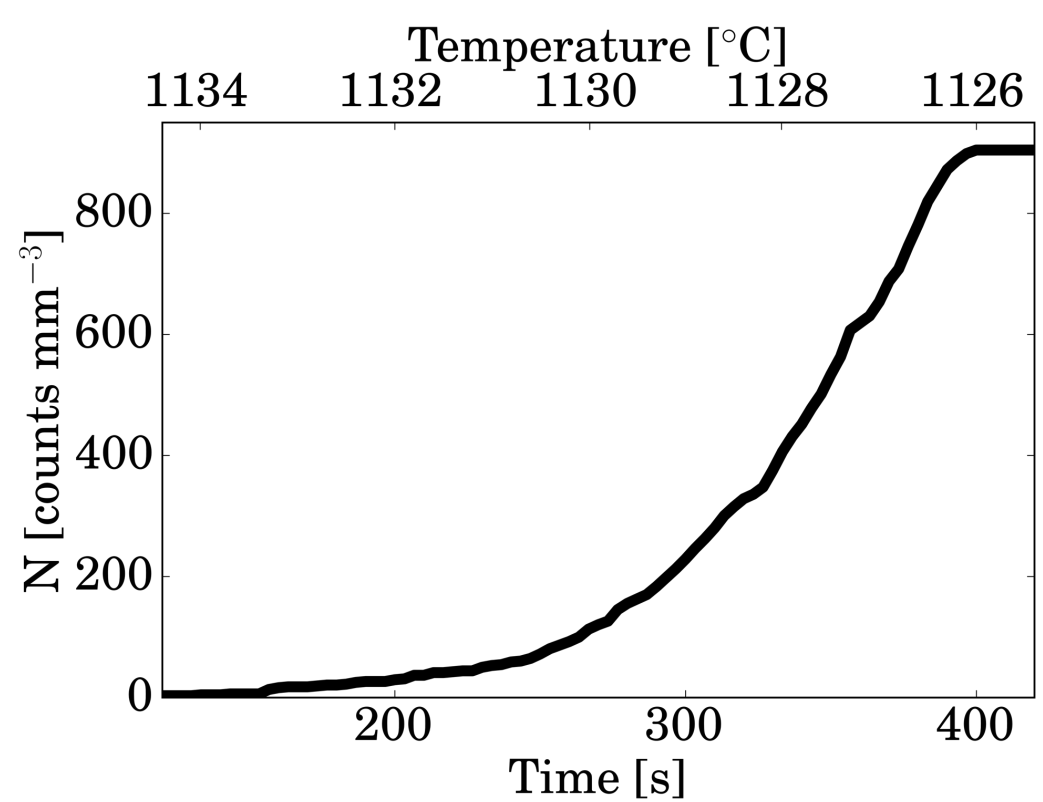

Figure 9. Density of nodules, $N$, as a function of time and temperature observed in the in situ experiment.

The distribution of equivalent nodule radii observed at 6 different instances of time is presented in figure 10. All distributions are normalised with respect to the final number of nodules. The equivalent nodule radius is obtained from the nodule volume gathered from tomograms rather than the cross sectional slices obtained from a 2D micrograph. This allows elimination of the related uncertainties as illustrated in references [2,43]. Figure 10 shows the size distribution evolution that develops from being almost uniform in the initial stages of solidification to become increasingly narrow with the maximum shifting towards larger radii during later stages of solidification. The significant shift in the nodule size distribution 
observed between $t=400 \mathrm{~s}$ and $480 \mathrm{~s}$ is associated with the fact that nucleation of nodules has ceased at this point while the existing nodules continue their growth, albeit at a relatively low rate. The data presented in figure 8 showed that the growth rate of large nodules is affected more by the decreasing availability of carbon than their smaller counterparts. This indicates why the distribution becomes increasingly narrow and bell shaped over time. The nodule size distribution displays more than one maximum at several time instances although nucleation is continuous. Size distributions with multiple maxima are usually interpreted as evidence for multiple stages of nucleation separated in time by recalescence as discussed for high cooling rates by Pedersen and Tiedje [44]. Figure 10 highlights that care should be taken when concluding on nucleation stages solely on the basis of the size distribution observed at room temperature.

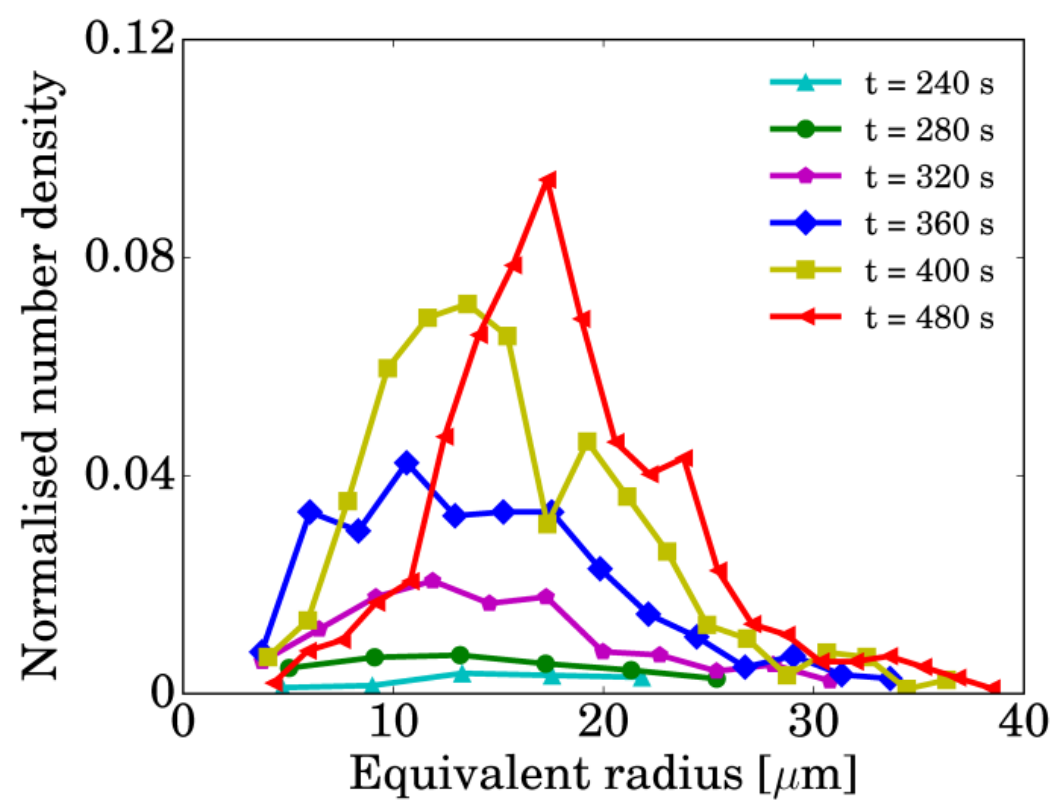

Figure 10. Normalised nodule size distribution obtained from in situ experiment at 6 different instances of time during solidification. Note that the bin width in the distribution varies for the 6 instances of time and that each size distribution has been normalised with respect to the final number of nodules.

The SoI model for nodule growth is now used to describe the development of the nodule size distribution during solidification. The models details are outlined in Supplementary note 1. To 
minimize errors in the model prediction the experimental nodule density is used as input for simulations. The thermal conditions used in the simulations were representative of those used during the in situ experiment. The solid fraction as a function of temperature estimated from the experiment is used as an input for $M$ ensuring a good basis for direct comparison between simulated and experimental results.

Figures 11 and 12 present the results of simulations using the UN model, i.e. equation (2), and the SoI model, equation (7), respectively. Note that the two figures are identical at $t=240 \mathrm{~s}$, $280 \mathrm{~s}$ and $320 \mathrm{~s}$ as the model modification in the present case only takes effect after $t=320 \mathrm{~s}$. Comparing with the experimental observations presented in figure 10 it is clear that the UN growth model results in a large overestimation of the radius associated to the maximum of the distribution. In general, the final size distribution is shifted towards larger radii as compared to the experimental data. The SoI growth model produces a much better prediction of the final distribution. In general, it seems that the overall shape of the size distributions in figure 12 resembles those observed in the experimental data (figure 10). However, the smallest nodules appear slightly over-represented in simulation results at $t=360 \mathrm{~s}$ and $400 \mathrm{~s}$. This might be due to an underestimation of the growth rates of the smallest nodules. It is possible that these nodules are not as heavily affected by the depletion of carbon from the matrix as new nodules form only in the liquid where there, presumably, is sufficient carbon available to limit the effects of the overall depletion of the matrix. This is also reflected by the fact that the UN model performs better in this respect. A possible solution to improve this prediction would be to exclude nodules below a certain radius from the effects of carbon depletion although it is unclear how such a cut-off threshold can be selected. 


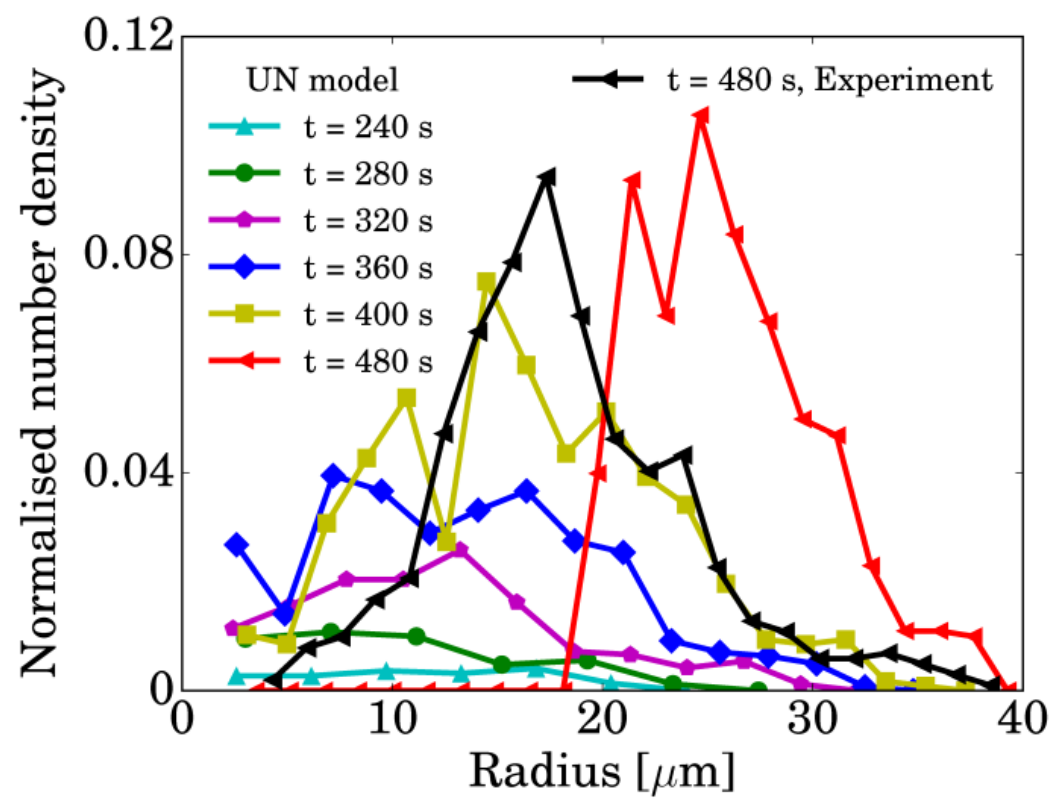

Figure 11. Predicted nodule size distribution at 6 different instances of time using the uninodular (UN) model as well as the experimental size distribution at $t=480 \mathrm{~s}$.

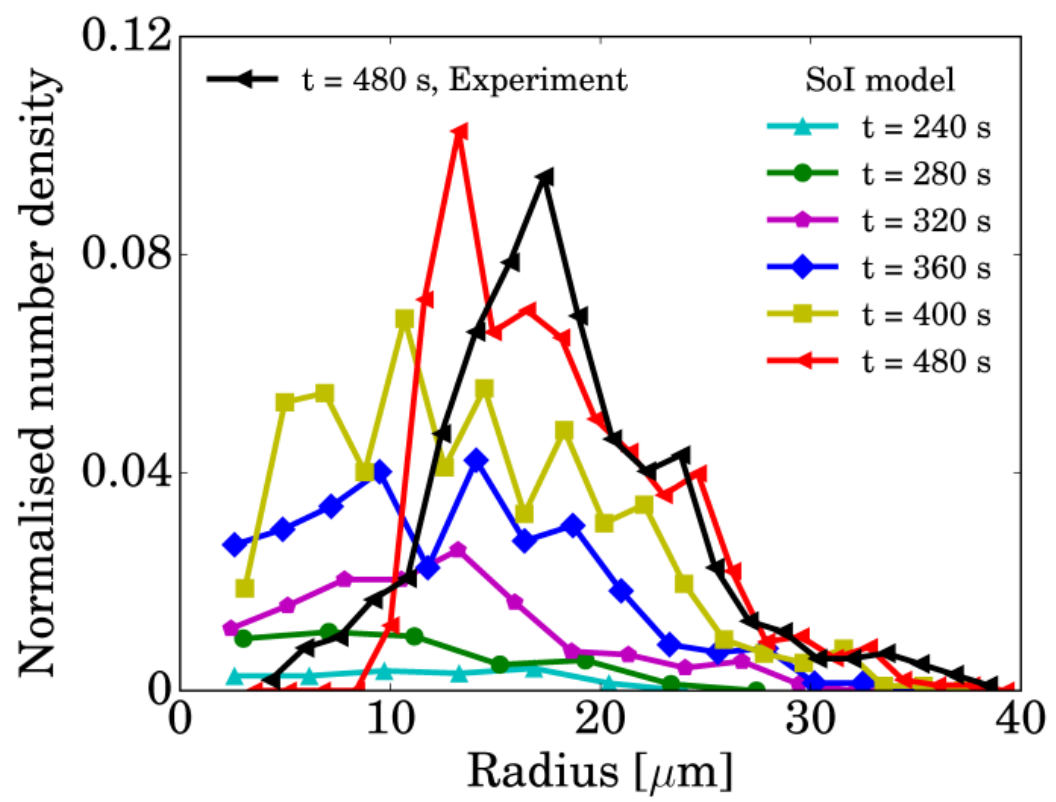

Figure 12. Predicted nodule size distribution at 6 different instances of time using the sphere of influence (SoI) model as well as the experimental size distribution at $t=480 \mathrm{~s}$.

A relevant comparison of the experimental and the simulation in the context of growth of nodules can be made by observing the median and average nodule radii, as shown in figures 13a-b. Clearly, the results from the UN and the SoI growth models overlap up to and including $t=320 \mathrm{~s}$. Then the effect of the new model modification becomes evident in the sense that the 
UN model significantly overestimates the final values of both the median and the average nodule radius. Using the SoI growth model the predicted median corresponds very well with the experimental observations confirming the validity of the model. However, the average nodule size is consistently underestimated. As previously discussed, irregular nodules tend to grow faster than their regular counterparts and also faster than predicted by the SoI model. Since the irregular nodules also nucleate relatively early they are found among the largest nodules in the size distribution. The fact that they are relatively few in numbers might explain why the model underestimates the average nodule radius but is able to predict the median nodule radius.

The presented comparison of simulated and experimental results show that the SoI growth model can successfully predict the overall shape of the nodule size distribution as well as the median nodule radius. It is, however, also clear that the SoI model represents the average nodule growth behaviour. Thus, the model might not provide accurate predictions when fastgrowing irregular nodules are present or if the conditions for nodules nucleating very late in the solidification process differ substantially from the model assumptions. The SoI model has been compared to a single experiment under conditions which in some aspects diverge from those of a casting process. However, the level of detail at which the model could be validated is unprecedented thus providing a strong foundation for the SoI model and supporting the use of the model to simulate DCI solidification under a wide range of process parameters and melt compositions.
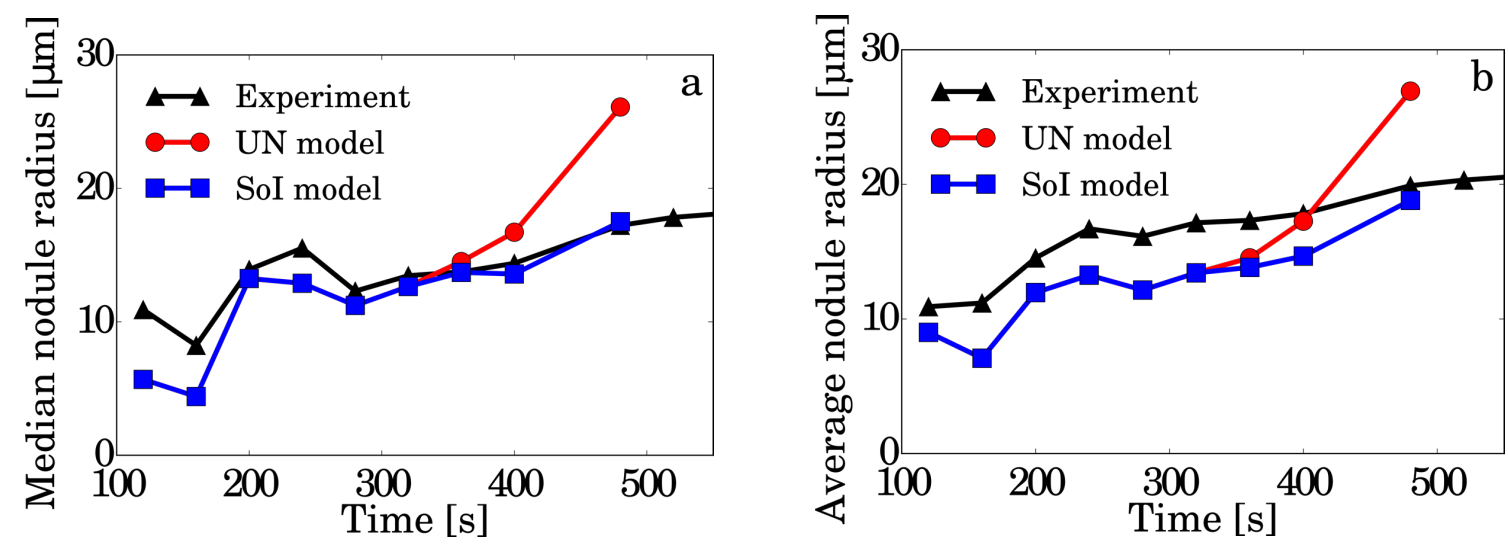
Figure 13. Median (a) and average (b) nodule radius as function of time from experiment as well simulations. Simulated results are obtained using either the uni-nodular (UN) or the sphere of influence (SoI) growth model.

\section{Conclusion}

The sphere of influence (SoI) model for graphite nodule growth has been suggested and discussed in relation to existing descriptions and validated against in situ observations of individual nodule growth as well as large population developments. The in situ observations obtained by synchrotron X-ray tomography provided a unique basis for model validation at an unprecedented level of detail. The main features of the sphere of influence model are:

- The effect of carbon depletion in the austenite matrix is taken into account.

- A criterion for imposing the effect of carbon depletion is developed based on considerations of overlapping diffusion fields. This criterion does not require predefined inputs in solidification simulations.

- The model is validated over a broad range of times and solid fractions as well as for both individual nodules and a large population.

The model validations have shown that the SoI model performs much better than the uninodular (UN) model in the sense that the gradual reduction in growth rate observed at late stages of solidification was well predicted. The UN model predicted large growth rates even towards the end of solidification resulting in considerable errors in the predicted final nodule size distribution. The presented model constitutes an important step towards the ability to accurately predict nodule size distributions after casting when combined with models describing the eutectoid transformation of the matrix.

\section{Acknowledgment}

This work would not have been possible without generously funding from Engineering and Physical Sciences Research Council (EPSRC, grant no. EP/I02249X/1) and Research Fund for Coal and Steel (RFCS, grant no. RFSR-PR-10005 DDT). MAA would also like to thank Research Complex at Harwell and University of Manchester in continuously supporting his research. 
MAA is also thankful to Ford Motor company for supporting his research during the writing of this paper. MKB was supported financially by the Strategic Research Centre 'REWIND', Danish Research Council for Strategic Research, grant no. 10-093966. The authors would like to thank Diamond Light Source (DLS), UK, especially the remarkable support they received from the I12 beamline staff, particularly, Dr. Robert Atwood, during the EE12204-1 beam time.

Data statement: Due to its large size, the underlying raw data is not shared online, but representative sample data is included in the figures and supplementary data. The entire datasets are stored at DLS, and are available from the authors on reasonable request.

\section{References}

[1] Tiedje N S 2010 Solidification, processing and properties of ductile cast iron Mater. Sci. Technol. 26 505-14

[2] Mukherjee K, Fæster S, Hansen N, Dahl A B, Gundlach C, Frandsen J O and Sturlason A 2017 Graphite nodules in fatigue-tested cast iron characterized in 2D and 3D Mater. Charact. 129 169-78

[3] Mullins J D 1990 Ductile iron data for design engineers. (Rio Tinto Iron \& Titanium Inc)

[4] Sonne M R, Thorborg J and Hattel J H 2017 Modelling the effect of coating on the stresses and microstructure evolution in chill casting of wind turbine main shafts Wind Energy 20 1635-43

[5] Ruvalcaba D, Mathiesen R H, Eskin D G, Arnberg L and Katgerman L 2007 In situ observations of dendritic fragmentation due to local soluteenrichment during directional solidification of an aluminum alloy Acta Mater. 55 4287-92

[6] Yasuda H, Yamamoto Y, Nakatsuka N, Yoshiya M, Nagira T, Sugiyama A, 
Ohnaka I, Uesugi K and K. 2009 In situ observation of solidification phenomena Int. J. Cast Met. Res. 22 15-21

[7] Limodin N, Salvo L, Boller E, Suéry M, Felberbaum M, Gailliégue S and Madi K 2009 In situ and real-time 3-D microtomography investigation of dendritic solidification in an Al-10wt.\% Cu alloy Acta Mater. 57 2300-10

[8] Clarke A J, Tourret D, Imhoff S D, Gibbs P J, Fezzaa K, Cooley J C, Lee W K, Deriy A, Patterson B M, Papin P A, Clarke K D, Field R D and Smith J L 2015 $\mathrm{X}$-ray imaging and controlled solidification of $\mathrm{Al}-\mathrm{Cu}$ alloys toward microstructures by design Adv. Eng. Mater. 17 454-9

[9] Kareh K M, Lee P D, Atwood R C, Connolley T and Gourlay C M 2014 Revealing the micromechanisms behind semi-solid metal deformation with time-resolved X-ray tomography Nat. Commun. 54464

[10] Puncreobutr C, Lee P D, Hamilton R W and Phillion A B 2012 Quantitative 3D characterization of solidification structure and defect evolution in $\mathrm{Al}$ alloys JOM 64 89-95

[11] Puncreobutr C, Phillion A B, Fife J L, Rockett P, Horsfield A P and Lee P D 2014 In situ quantification of the nucleation and growth of Fe-rich intermetallics during Al alloy solidification Acta Mater. 79 292-303

[12] Puncreobutr C, Lee P D, Kareh K M, Connolley T, Fife J L and Phillion A B 2014 Influence of Fe-rich intermetallics on solidification defects in $\mathrm{Al}-\mathrm{Si}$ Cu alloys Acta Mater. 68 42-51

[13] Shuai S, Guo E, Phillion A B, Callaghan M D, Jing T and Lee P D 2016 Fast synchrotron X-ray tomographic quantification of dendrite evolution during the solidification of MgSn alloys Acta Mater. 118 260-9 
[14] Karagadde S, Lee P D, Cai B, Fife J L, Azeem M A, Kareh K M, Puncreobutr C, Tsivoulas D, Connolley T and Atwood R C 2015 Transgranular liquation cracking of grains in the semi-solid state. Nat. Commun. 68300

[15] Azeem M A, Lee P D, Phillion A B, Karagadde S, Rockett P, Atwood R C, Courtois L, Rahman K M and Dye D 2017 Revealing dendritic pattern formation in $\mathrm{Ni}, \mathrm{Fe}$ and Co alloys using synchrotron tomography Acta Mater. 128 241-8

[16] Yamane K, Yasuda H, Sugiyama A, Nagira T, Yoshiya M, Morishita K, Uesugi K, Takeuchi A and Suzuki Y 2015 Influence of Mg on Solidification of Hypereutectic Cast Iron: X-ray Radiography Study Metall. Mater. Trans. A $1-10$

[17] Azeem M, Bjerre M, Atwood R, Tiedje N and Lee P 2018 Synchrotron quantification of graphite nodule evolution during the solidification of cast iron Acta Mater. 155 393-401

[18] Rivera G, Boeri R and Sikora J 2002 Revealing and characterising solidification structure of ductile cast iron Mater. Sci. Technol. 18 691-7

[19] Selig C and Lacaze J 2000 Study of microsegregation buildup during solidification of spheroidal graphite cast iron Metall. Mater. Trans. B 31B 827-36

[20] Källbom R, Hamberg K, Wessén M and Björkegren L-E E 2005 On the solidification sequence of ductile iron castings containing chunky graphite Mater. Sci. Eng. A 413-414 346-51

[21] Vazehrad S, Elfsberg J and Diószegi A 2015 Study of microstructure and silicon segregation in cast iron using color etching and electron microprobe 
analysis Mater. Charact. 104 132-8

[22] Freulon A, de Parseval P, Josse C, Bourdie J and Lacaze J 2016 Study of the Eutectoid Transformation in Nodular Cast Irons in Relation to Solidification Microsegregation Metall. Mater. Trans. A Phys. Metall. Mater. Sci. 47 5362-71

[23] Lacaze J, Bourdie J and Castro-Román M J 2017 A 2-D nucleation-growth model of spheroidal graphite Acta Mater. 134 230-5

[24] Wetterfall S-E, Fredriksson H and Hillert M 1972 Solidification process of nodular cast iron J. Iron Steel Inst. $210323-33$

[25] Lesoult G, Castro M and Lacaze J 1998 Solidification of spheroidal graphite cast iron - I. Physcial modelling Acta Metall. 46 983-95

[26] Bjerre M 2017 In situ observations of graphite formation during solidification of cast iron (Technical University of Denmark). URL: http://orbit.dtu.dk/files/143774166/Mathias_Karsten_Bjerre_PhD_Thesis. pdf

[27] Boeri R E 1989 The solidification of ductile cast iron (The University of British Columbia)

[28] Su K C, Ohnaka I, Yamauchi I and Fukusako T 1985 Computer Simulation of Solidification of Nodular Cast Iron Proc of the Int Symp on the Metall of Cast Iron, 3rd ed H Fredriksson and M Hillert (Stockholm) pp 181-90

[29] Escobar A, Celentano D, Cruchaga M, Lacaze J, Schulz B, Dardati P and Parada A 2014 Experimental and numerical analysis of effect of cooling rate on thermal-microstructural response of spheroidal graphite cast iron solidification Int. J. Cast Met. Res. 27 176-86 
[30] Lacaze J, Castro M and Lesoult G 1998 Solidification of spheroidal graphite cast irons - II. Numerical simulation Acta Metall. 46 997-1010

[31] Dardati P M, Celentano D J, Godoy L A, Chiarella A A and Schulz B 2009 Analysis of ductile cast iron solidification: numerical simulation and experimental validation Int. J Cast Met. Res. 22 390-400

[32] Pedersen K M, Hattel J H and Tiedje N 2006 Numerical modelling of thinwalled hypereutectic ductile cast iron parts Acta Mater. 54 5103-14

[33] Bjerre M, Tiedje N, Thorborg J and Hattel J 2015 Modelling the solidification of ductile cast iron parts with varying wall thicknesses IOP Conf. Ser. Mater. Sci. Eng. 8412038

[34] Bjerre M, Azeem M, Lee P, Hattel J and Tiedje N 2018 Revisiting models for spheroidal graphite growth Materials Science Forum vol 925 (Trans Tech Publications) pp 118-24

[35] Atwood R C, Sridhar S and Lee P D 1999 Equations for nucleation of hydrogen gas pores during solidification of aluminum seven weight percent silicon alloy Scr. Mater. 41 1255-9

[36] Atwood R C, Sridhar S, Zhang W and Lee P D 2000 Diffusion-controlled growth of hydrogen pores in aluminium-silicon castings: In situ observation and modelling Acta Mater. 48 405-17

[37] Scheil E, Hütter L, Sheil E and Hütter L 1953 Untersuchung über Kristallisation des Gußeisens mit Kugelgraphit Arch. für das Eisenhüttenwes. 24 237-46

[38] Underwood E E 1970 Quantitative Stereology (Reading, Mass.: AddisonWesley) 
[39] Pedersen K M 2006 Solidification and Microstructure of Thin Walled Ductile Cast Iron (Technical University of Denmark). URL: http://orbit.dtu.dk/files/5092954/Solidification\%20and\%20microstructu re\%20of\%20thin\%20walled\%20ductile\%20cast\%20iron.pdf

[40] Lee P D and Hunt J D 1997 Hydrogen porosity in directional solidified aluminium-copper alloys: In situ observation Acta Mater. 45 4155-69

[41] Murcia S C, Ossa E A and Celentano D J 2014 Nodule evolution of ductile cast iron during solidification Metall. Mater. Trans. B Process Metall. Mater. Process. Sci. 45 707-18

[42] Muhmond H M and Fredriksson H 2012 Relationship Between Inoculants and the Morphologies of MnS and Graphite in Gray Cast Iron Metall. Mater. Trans. B 44 283-98

[43] Chuang C, Singh D, Kenesei P, Almer J, Hryn J and Huff R 2018 Application of X-ray computed tomography for the characterization of graphite morphology in compact-graphite iron Mater. Charact. 141 442-9

[44] Pedersen K M and Tiedje N S 2008 Graphite nodule count and size distribution in thin-walled ductile cast iron Mater. Charact. 59 1111-21 